\title{
New row erupts about lab. animals
}

DC indictment stirs welfare

\section{groups' protests}

\section{Washington}

Public pressure for tighter laws on the use of laboratory animals has been increased by the indictment of the head of a private laboratory on the criminal charge of causing pain and suffering to monkeys. The case against Dr Edward Taub, chief investigator at the Institute of Behavioral Research in Silver Spring, Maryland, is a particular embarrassment to the National Institutes of Health (NIH), the source of Dr Taub's research contract.

Last week, animal welfare groups told a congressional subcommittee that the case demonstrates that the existing Animal Welfare Act, and its interpretation by NIH, lacks sufficient bite. Medical research organizations, keen to avoid new federal controls, countered that peer pressure and the existing guidelines were sufficient to minimize necessary suffering, and that researchers are aware that healthy animals make for better science.

The charges against Dr Taub, who had been using the monkeys for research into the recovery of stroke victims, were based on complaints made by $\mathrm{Mr}$ Alex Pacheco, a member of a group known as People for the Ethical Treatment of Animals. He had taken a job as a laboratory assistant at the institute, and collected data and photographs, which he used to support charges of mistreatment and unsanitary conditions.

$\mathrm{Mr}$ Pacheco reported his findings to the police, who have jurisdiction over the treatment of laboratory animals since Maryland is one of the few states with its own Animal Cruelty Law from which laboratories are not exempt. The police raided the laboratory early on the morning of 11 September and reported that among other things they found "monkeys in such physical and mental distress that they appeared to have bitten off their fingers and arms" - reactions which Dr Taub said were the result of removing sensation from these limbs to discover the effects on their subsequent use.

Dr Taub protests his innocence to the charges of cruelty, which if proven carry a fine of $\$ 1,000$ or 90 days in gaol, and says that Mr Pacheco's claims are based on distortion of the facts and misunderstanding of the research.

However, the case has already proved a considerable embarrassment to NIH, which have withdrawn a $\$ 200,000$ grant to the laboratory on the basis of an internal investigation, but now face accusations that review and inspection procedures designed to prevent cruelty to laboratory animals are inadequate.

Animal welfare groups claim various inadequacies in the current law. For example, neither the Animal Welfare Law of 1970 , nor amendments passed in 1976 cover rats, mice or farm animals, the most widely used groups in biomedical research.

Several bills have been introduced into Congress in the past few years to tighten up the existing law and two in particular are receiving enthusiastic support from the animal welfare community.

One would place more responsibility in the hands of institutions at which research is carried out, as well as authorize the Secretary of Health and Human Services - responsible for the NIH research programmes - to appoint an advisory committee with public representatives to keep track of the administration of anima welfare regulations. The second bill would increase support for research into alternatives to the use of live animals in research.

Some animal welfare groups want the rules to go further, for example requiring all research institutions using laboratory animals to establish animal welfare committees, with public representatives, to provide comparable protection to that given to humans used in research.

These moves are being resisted by the research community. At a hearing of the science, research and technology subcommittee of the House of Representatives Science and Technology Committee, witnesses from groups such as the American Institute of Biological Sciences, the Association of American
Universities, the National Society for Medical Research and the Association of American Medical Colleges, each argued that although existing procedures could be improved, the proposed quantum increase in regulation is unnecessary.

There was even stronger criticism of a proposal that up to 50 per cent of all NIH funds now used for work on live animals should eventually be restricted to comparable research on animal substitutes.

The research community hopes that outside criticism can be contained through a process of gradual evolution. They point out that largely because of increasing costs of maintaining animal facilities, the use of live animals in research declined by 40 per cent between 1968 and 1978. They also point to recent increases in the allocation of research funds to look at animal alternatives. Last month, for example, the Cosmetic, Toiletry and Fragrance Association announced that it was making a grant of $\$ 1$ million to the Johns Hopkins School of Hygiene and Public Health in Baltimore to establish a centre for developing alternatives to animals for testing the safety of commercial products.

Whether the process of gradual change supported by the industry, NIH and by most of the research community will be sufficient to hold off new legislation remains to be seen. A decade ago, evidence such as that produced by $\mathrm{Mr}$ Pacheco would have virtually guaranteed the imposition of stiff new restrictions on research. But today the political environment discourages more regulation or public participation in the control of research.

\section{Handler awarded Medal of Science}

\section{Washington}

Dr Philip Handler, who retired earlier this year after twelve years as president of the US National Academy of Sciences, has been awarded the National Medal of Science, America's highest scientific award, by President Ronald Reagan for his "outstanding contribution to biochemical research" as well as for his "national leadership" in furthering the state of American science.

A statement issued last week by the White House said of Dr Handler, who was chairman of the National Science Board from 1962 to 1970 , and was first elected president of the National Academy of Sciences in 1969, that "his strong and eloquent leadership of the Academy during turbulent times for science was praised widely by the scientific community on the occasion of his recent retirement"'.

The citation also refers to $\mathrm{Dr}$ Handler's research that led to a clearer understanding of pellagra. Dr Handler, who stepped down from his academy post at the end of June, has recently been seriously ill and is receiving treatment in a hospital in Boston.

David Dickson

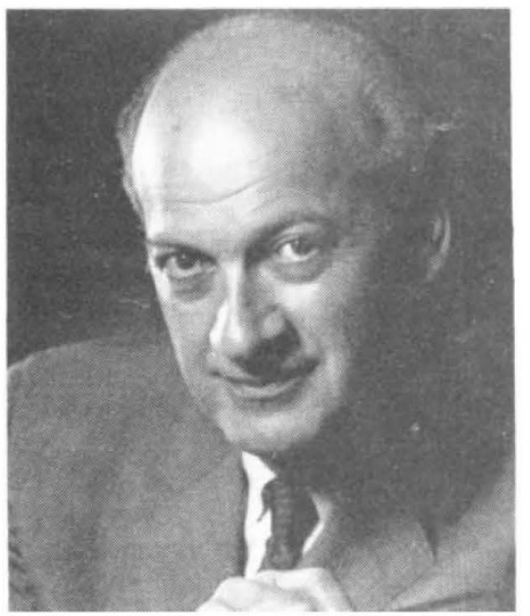

Philip Handler, medallist 